\title{
Adrenal Insufficiency Secondary to Exogenous Use of Dermatological Steroid
}

\author{
Abdulrahman A. Al Shaikh, FrCP(UK) \\ Department of Medicine, Faculty of Medicine, \\ King Abdulaziz University, Jeddah, Saudi Arabia
}

\begin{abstract}
During years 2000 and 2003, a total of 146 patients were diagnosed to have adrenal insufficiency due to exogenous use of steroid. $20(13.69 \%)$ of these patients were diagnosed to have pituitaryadrenal suppression secondary to exogenous use of dermatological steroid. The objective of the study is to identify the duration of steroid use, clinical presentation and the results of the assessment of pituitaryadrenal axis. Fatigability, body pain, and abdominal pain were the main symptoms at presentation. All of these patients showed signs of Cushing's syndrome (chronic high steroid exposure). Low urinary and serum cortisone levels, low adrenocorticotropic hormone levels and blunt response to adrenocorticotropic hormone injection were found in all patients. Symptoms of patients improved with replacement therapy with oral steroids. We concluded that local dermatological steroid preparations has similar complication on the pituitary-adrenal axis as the other routes of systemic steroid administration but with prolonged period of exposure for a year or more.
\end{abstract}

Keywords: Dermatological steroid, Adrenal insufficiency, Adrenocorticotropic hormone.

\section{Introduction}

The clinical diagnosis of chronic adrenal insufficiency at times is difficult to identify unless there is clinical awareness of the disease. Diagnosis is often obvious when classic symptoms and signs are present. However, early symptoms

Correspondence \& reprint requests to: Dr. Abdulrahman A. Al Shaikh

P. O. Box 80215, Jeddah 21589 Saudi Arabia

Accepted for publication: 23 February 2005. Received: 25 January 2004. 
such as lassitude and fatigability are nonspecific ${ }^{[1]}$. Suppression of hypothalamic - pituitary - adrenal function with chronic administration of high doses of glucocorticoids is the most common cause of adrenal insufficiency ${ }^{[2]}$. Chronic corticosteroid therapy is used in the treatment of a variety of disorders because of its potent anti-inflammatory effect and, occasionally, because it is thought to have immunosuppressive activity ${ }^{[3]}$. Many medical illnesses have been treated with systemic steroid, adrenal insufficiencies have been reported in most of them when the use exceeded more than a month. Dermatological use of steroids are used commonly and expected to have similar effects on the adrenal as the systemic steroid depending on the area, amount and the duration of use ${ }^{[3]}$. We usually overlook this problem because the presenting symptoms are insidious and non-specific, hence, there should be a high index of suspicion, therefore a good history and examination should be conducted on all patients on prolonged therapy. The purpose of the study was to determine the type of steroid, site and duration of application, clinical presentation and the results of investigations.

\section{Methods}

A retrospective study conducted at King Abdulaziz University Hospital (KAUH) between the period of June 2000 and December 2003. Charts of all patients diagnosed to have secondary adrenal insufficiency due to exogenous use of local steroids were reviewed for age, sex, symptoms of adrenal insufficiency, indication of steroid use; site and duration of use were noted. Presenting complaints of the patients were fatigability and weakness. Diagnosis of adrenal insufficiency was based on the history of steroid use, signs of adrenal insufficiency or Cushing's syndrome, low $24 \mathrm{~h}$ urine hydrocortisone level, and low adrenocorticotropic hormone (ACTH) levels. Hydrocortisone level in the urine was done by fluorescence polarization immunoassay with normal value of $32-243 \mu \mathrm{g} / 24 \mathrm{~h}$, and ACTH was done by chemiluminiscent immunometric assay with low limit of $10 \mathrm{pg} / \mathrm{ml}$ and high limit $40 \mathrm{pg} / \mathrm{ml}$. All patients underwent assessment of pituitary adrenal axis by insulin stress test and ACTH stimulation test. Synacthen (synthetic ACTH) stimulation test was done by determination of the basal serum steroid level and at 30, 60, and 90 min after administered 250 mg of synthetic ACTH (Synacthen) intramuscularly. Insulin stress test was done by giving short acting insulin 0.1 units $/ \mathrm{kg}$ intravenously, to induce hypoglycemia, where blood sugar levels checked every $15 \mathrm{~min}$ and hydrocortisone levels every $30 \mathrm{~min}$ for $2 \mathrm{~h}$.

\section{Results}

One hundred and forty-six (146) patients were diagnosed to have adrenal insufficiency; twenty (13.69\%) patients were due to exogenous dermatological 
use of steroid. Dermatological steroids were prescribed by physicians in 16 $(80 \%)$ patients, but only $2(10 \%)$ patients continued their follow-up.

All $(100 \%)$ patients presented to the clinic with generalized body weakness and fatigability. Upper abdominal pain and repeated vomiting was present in thirteen $(65 \%)$ patients which responded to oral steroid replacement. Complaints of the patients started six months after discontinuing of the local preparations. Average duration of use was more than one year where 5 of the patients used it for more than 3 years.

Classical features of adrenal insufficiency were not present in these patients. Features of chronic exposure to high steroid - Cushing's syndrome - were clear in form of plethoric face, central obesity and abdominal stria all $20(100 \%)$ patients (Table 1). Extremities were the prevalent areas of application of the dermatological steroid, followed by the neck and the face.

TABLE 1. The common findings at presentation.

\begin{tabular}{|l|c|c|}
\hline \multicolumn{1}{|c|}{$\begin{array}{c}\text { Symptoms, Signs } \\
\text { and Investigations }\end{array}$} & $\begin{array}{c}\text { Number of } \\
\text { Patients }\end{array}$ & Percentage \\
\hline 1. Fatigability & 18 & $90.0 \%$ \\
\hline 2. Increased Weight & 20 & $100.0 \%$ \\
\hline 3. Plethoric Face & 20 & $100.0 \%$ \\
\hline 4. Buffalo Hump & 20 & $100.0 \%$ \\
\hline 5. High Blood Pressure & 0 & $0.0 \%$ \\
\hline 6. Exophthalmos & 2 & $10.0 \%$ \\
\hline 7. Abdominal Stria & 18 & $90.0 \%$ \\
\hline 8. Diabetes Mellitus & 8 & $40.0 \%$ \\
\hline 9. Low Serum Potassium & 0 & $0.0 \%$ \\
\hline 10. Low Urinary Cortisol & 20 & $100.0 \%$ \\
\hline 11. Low ACTH & 20 & $100.0 \%$ \\
\hline 12. Blunted response to ACTH & 20 & $100.0 \%$ \\
\hline
\end{tabular}

$\mathrm{ACTH}=$ adrenocorticotropic hormone

Eight (40\%) patients developed diabetes mellitus even after discontinuing the use of the local steroid and all of these patients were treated with oral antihyperglycemic drugs. Blood pressure was normal in all with no postural hypotension. Eczema was found to be the most constant indication of use in 18 $(90 \%)$ of patients while two (2) for bleaching or whitening of the face. Electrolyte and creatinine levels were normal in all of them. Urinary free cortisol was sub normal to low normal, in the range of $20-67 \mu \mathrm{g} / 24 \mathrm{~h}$ with the median 
level of $29 \mu \mathrm{g} / 24 \mathrm{~h}$ in all $20(100 \%)$ patients ACTH level was low and ranged between $7-16 \mathrm{pg} / \mathrm{ml}$ with median level of $9 \mathrm{pg} / \mathrm{ml}$ in all (100\%). Blunted pituitary adrenal axis to either insulin stress test or ACTH stimulation test was observed in all cases. Replacement therapy with physiological doses of steroid was given to all the patients with significant improvement in their symptoms.

\section{Discussion}

Prolonged administration of pharmacologic doses of synthetic glucocorticoid is the most common cause of ACTH deficiency and consequent adrenal insufficiency (secondary adrenal insufficiency or tertiary). High doses of glucocorticoid decrease corticotrophin releasing hormone (CRH) synthesis and secretion from the hypothalamus; they also block the trophic and ACTHsecretagogue action of the anterior pituitary. These results in decreased synthesis of pro-opiomelanocortin (POMC) and decreased secretion of ACTH and other POMC-related peptides by the pituitary corticotrophs ${ }^{[2]}$.

In the absence of ACTH stimulation, the zona fasciculata and zona reticularis of the adrenal gland atrophy and no longer produce enough cortisol. Cortisol secretion can be restored by prolonged $\mathrm{ACTH}$ administration, a feature that is used to distinguish secondary or tertiary from primary adrenal insufficiency. The common presenting symptoms in patients with adrenal insufficiency are fatigue and lassitude ${ }^{[4]}$. In this study, all of the patients presented with fatigue and weakness. Because of exposure to high dose steroids for a long period of time these patients present with signs of Cushing's syndrome, these signs depend on the dose and duration of steroid use ${ }^{[5]}$. Cushingoid features like truncal obesity, buffalo hump, moon face; and weight gain were found in all of our patients. Hyperpigmentation was not seen, as plasma ACTH concentration is not high in these patients. Dehydration was not present and hypotension was less prominent because of relatively normal aldosterone level ${ }^{[1,6]}$. Hypernatremia, but not hyperkalemia, may be present, reflecting the presence of mineralocorticoid activity and the absence of glucocorticoid suppression of vasopressin secretion. Blood pressure was normal in all of the patients with no postural change.

Gastrointestinal (GI) symptoms were less common in our patients, thirteen (65\%) patients presented with upper abdominal pain and vomiting which is comparable to other reports in the literature, these symptoms resolved with replacement therapy with oral steroids ${ }^{[7]}$. The cause of GI symptoms in adrenal insufficiency is not known. Gasteroduodenoscopy and radiology are usually normal, gastric emptying may be delayed ${ }^{[8]}$. It usually responds to steroid treatment ${ }^{[7]}$. Skin thinning and purpura are one of the common side effects of prolonged steroid use and were found in eleven $(55 \%)$ of our patients ${ }^{[9]}$. It has 
been suggested that cataract formation is a dose and time dependent side effect that rarely occurs with prednisone doses less than $10 \mathrm{mg} /$ day, or with treatment for less than one year ${ }^{[10]}$. However, others believe that there is no minimal safe dose with respect to this complication ${ }^{[11,12]}$. In our patients six $(30 \%)$ were diagnosed to have cataract and all of them were above the age of 50-years old. Exophthalmos - swelling of the eye lid, and ocular muscles, rare steroid complications, was seen in two $(10 \%)$ of our patients ${ }^{[13,14]}$. Glucocorticoids have a variety of actions that lead to hyperglycemia, but only rarely to increased ketone production ${ }^{[15,16]}$.

As these study's patients, eight were diagnosed to have diabetes during the use of steroid and even remained diabetic after discontinuing it. Identifying the degree of hypothalamic pituitary axis (HPA) suppression is not simple clinically. Plasma or urinary free cortisol secretion may be low but may not reflect the HPA reserve. However, significant suppression of the HPA is unlikely if it is in the upper half of the normal range. These parameters probably return to normal quickly as the HPA recovers, but they can not be considered as a good indicator of adrenal responsiveness to stress ${ }^{[17]}$. The response to administration of synthetic ACTH is the preferred method to assess adrenocortical function. It does not, however, provide information about hypothalamic function and, therefore, may be normal in patients with hypothalamic or pituitary insufficiency. The best test of response to stress, when done carefully, is measurement of plasma cortisol levels during insulin - induced hypoglycemia, which can frequently be abnormal for a long period, even after corticosteroid use ${ }^{[17]}$. Patients in this study showed low free urinary cortisol, and poor pituitary and adrenal reserve to high ACTH stimulation and insulin induced hypoglycemia.

\section{Conclusion}

From our study we concluded that even skin preparation of steroids has similar side effects on the pituitary adrenal axis as the other routes of steroid administration but with longer duration of exposure. This should generate awareness amongst physicians of such possible complications and watch for signs and symptoms of adrenal suppression in such patients. More studies are needed to know whether less duration of therapy will have similar effect on the adrenal pituitary axis.

\section{References}

[1] Burke CW. Adrenocortical insufficiency. Clin Endocrinol Metab 1985; 14(4): 947-976.

[2] Phifer RF, Spicer SS, Orth DN. Specific demonstration of the human hypophyseal cells which produce adrenocorticotropic hormone. J Clin Endocrinol Metab 1970; 31(4): $347-$ 361. 
[3] Kirwan Jr. Systemic corticosteroids in rheumatology. In: Rheumatology, Ed. Klippel, JH, Dieppe PA. St. Louis : Mosby, 1994. 8-11.

[4] Dunlop D. Eighty-six cases of Addison's disease. Br Med J 1963; 5362: 887-891.

[5] Shubin H. Long term (five or more years) administration of corticosteroids in pulmonary diseases. Dis Chest 1965; 48(3): 287-290.

[6] Parks JS, Brown MR, Hurley DL, Phelps CJ, Wajnrajch MP. Heritable disorders of pituitary development. J Clin Endocrinol Metab 1999; 84(12): 4362-4370.

[7] Valenzuela GA, Smalley WE, Schain DC, Vance ML, McCallum RW. Reversibility of gastric dysmotility in cortisol deficiency. Am J Gastroenterol 1987; 82(10): 1066-1068.

[8] Tobin MV, Aldridge SA, Morris AI, Belchetz PE, Gilmore IT. Gastrointestinal manifestations of Addison's disease. Am J Gastroenterol 1989; 84(10): 1302-1305.

[9] Fries JF, Williams CA, Ramey D, Bloch DA. The relative toxicity of disease-modifying antirheumatic drugs. Arthritis Rheum 1993; 36(3): 297-306.

[10] Black RL, Oglesby RB, von Sallman L, Bunim JJ. Posterior subcapsular cataract induced by corticosteroid in patients with rheumatoid arthritis. JAMA 1960; 174: 166-171.

[11] Berkowitz JS, David DS, Sakai S, Shoji H, Cheigh JS, Riggio RR, Stenzel KH, Rubin AL. Ocular complications in renal transplant recipients. Am J Med 1973; 55(3): 492-495.

[12] Skalka HW, Prchal JT. Effect of corticosteroids on cataract formation. Arch Ophthalmol 1980; 98(10): 1773-1777.

[13] Slansky HH, Kolbert G, Gartner S. Exophathalmos induced by steroids. Arch Ophthalmol 1967; 77(5): 578-581.

[14] Crew SJ. Adverse reaction to corticosteroid in the eye. Proc R Soc Med 1965; 58: 533.

[15] Olefsky JM, Kimmerling G. Effects of glucocorticoids on carbohydrate metabolism. Am J Med Sci 1976; 271(2): 202-210.

[16] McMahon M, Gerich J, Rizza R. Effects of glucocorticoids on carbohydrate metabolism. Diabetes Metab Rev 1988; 4(1): 17-30.

[17] Livanou T, Ferriman D, James VH. Recovery of hypothalamo-pituitary-adrenal function after corticosteroid therapy. Lancet 1967; 2(7521): 856-859. 


\title{
قصور وظيفة الغدة الكظرية لدى الذين يستخدمون السترويدات عن طريق الجلد
}

\author{
عبدالرحمن عبدالمحسن الشيخ

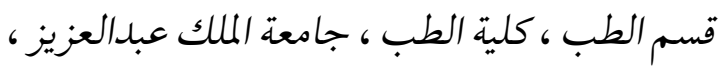

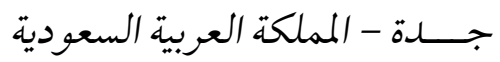

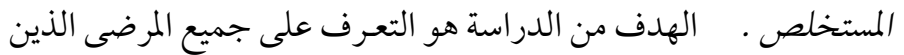

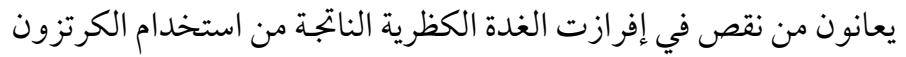

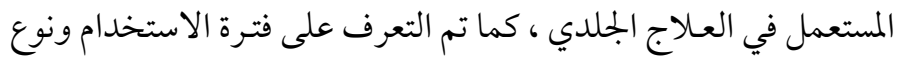

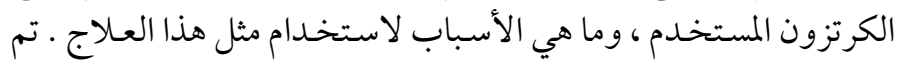

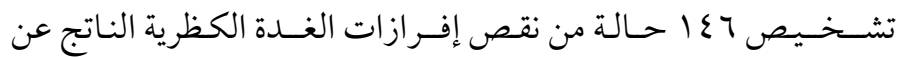

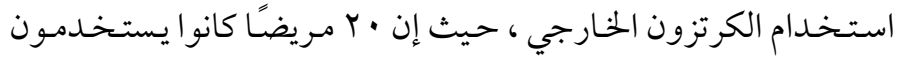

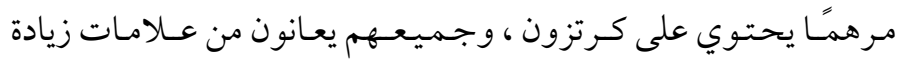

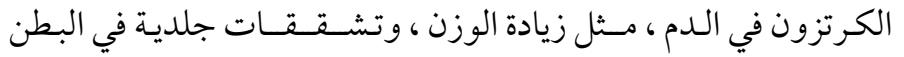

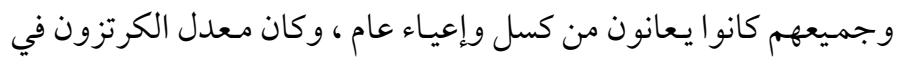

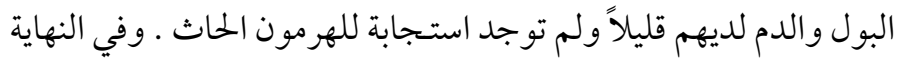

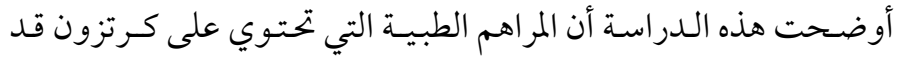

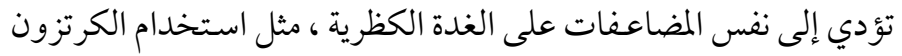

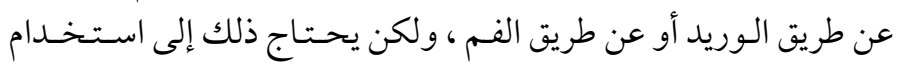
لفترة أطول . 